\title{
EXPLAINING THE EFFECTIVENESS OF FOREST AND WATER MANAGEMENT AND ITS SPATIAL DISTRIBUTION IN THE METROPOLITAN DISTRICT OF QUITO
}

\author{
Pablo Cabrera-Barona ${ }^{*}$, Paúl Cisneros ${ }^{2}$ \\ ${ }^{1}$ Facultad Latinoamericana de Ciencias Sociales, Quito, Ecuador \\ Instituto de Altos Estudios Nacionales, Quito, Ecuador \\ *Corresponding author: pfcabrera@flacso.edu.ec \\ Received: June $5^{\text {th }}, 2020$ / Accepted: February 16 ${ }^{\text {th }}, 2021$ / Published: April $1^{\text {st }}, 2021$ \\ https://DOI-10.24057/2071-9388-2020-106
}

\begin{abstract}
The effective implementation of Sustainable Development Goals (SDGs) related to forests (SDG15) and water resources (SDG6) have significant implications for achieving quality of life for people in urban and rural areas. We carried out a study in the rural parishes of the Metropolitan District of Quito (MDQ), Ecuador. The objective of the study was to assess how biophysical factors, institutional capacity and institutional complexity influence the perceived effectiveness of forest and water management. Ordinal logistic regressions were applied and spatial lag regressions were also calculated to assess the possible spatial correlation of the dependent variables. Additionally, spatial autocorrelation analyses (Gi* and Anselin Local Moran's I) were applied to assess the perceived effectiveness. The regressions results show that the number of stakeholders involved in the management of each resource, used as a proxy for institutional complexity, was a significant variable ( $p$-value $=0.003$ for forest resource management and $p$-value $=0.027$ for water resource management) when explaining perceived effectiveness. The spatial autocorrelation results show spatial hotspots ( $90 \%$ and $99 \%$ confidence) and a cluster (95\% confidence) of forest management effectiveness as well as some spatial outliers (95\% confidence) of water and forest management effectiveness. These findings were put in context to assess the current institutional arrangements used by local actors to implement SDGs 6 and 15. The results obtained may be useful for improving local public policies that seek integrated implementation for SDGs 6 and 15, while the applied methods can be transferred to the study of other SDGs
\end{abstract}

KEY WORDS: localization, policy effectiveness, local governments, water, forest, spatial analysis

CITATION: Pablo Cabrera-Barona, Paúl Cisneros (2021). Explaining The Effectiveness Of Forest And Water Management And Its Spatial Distribution In The Metropolitan District Of Quito. Geography, Environment, Sustainability, Vol.14, No 1, p. 53-62

https://DOI-10.24057/2071-9388-2020-106

ACKNOWLEDGEMENTS: We would like to acknowledge the support received from Victor López and Janett Ulloa during data collection. The Instituto de Altos Estudios Nacionales financed field work for data collection for this project.

Conflict of interests: The authors reported no potential conflict of interest.

\section{INTRODUCTION}

The localization of Sustainable Development Goals (SDGs) is a keystone for achieving the ambitious transformation proposed by the 17 objectives contained in Agenda 2030. According to the UN, localization is the «process of defining; implementing; and monitoring strategies at the local level for achieving global, national and subnational sustainable goals and targets» (United Nations Development Programme 2014). Localization relies heavily on local governments to implement context-relevant interventions in interaction with other actors (Slack 2014; Reddy 2016). Effective natural resources management is one of the areas where cooperation among government and non-governmental actors is required to implement interventions that act upon the characteristics of the locale within broader policy directives (K. P. Andersson and Ostrom 2008). However, it is well documented that local governments in the Global South often exhibit low institutional capacity and lack the financial resources needed to contribute to the effective implementation of public interventions required by the SDGs (Eakin and Lemos 2006; Xue, Weng and Yu 2018). Therefore, our main research questions relate to how to characterize the effectiveness of forest and water management in local rural areas and how does the effectiveness vary spatially?

Among the 17 objectives of Agenda 2030, UN member states have prioritized issues such as ensuring access to water and sanitation for all (SDG6) and achieving the sustainable management of forests (SDG15). Additionally, according to SDG 11, which calls to «Make cities and human settlements inclusive, safe, resilient and sustainable», subnational governments as well as local communities, private and non-governmental sectors must work together towards supporting positive economic, social and environmental links between urban, peri-urban and rural areas.

The effective implementation of SDGs related to water and forests in rural areas is fundamental to maintain and improve the quality of life for urban dwellers, especially 
for those living in the Global South (Okunola 2016). Additionally, the capacity of ecosystems to maintain their essential functions directly influences people's well-being in rural areas where livelihood is highly dependent on forested land and water resources (Belay and Bewket 2015).

Despite the long-term interest in investigating environmental decentralization at the local level, empirical studies on how local governance conditions affect the political priority received by different SDGs are only emerging (see Cisneros, Cabrera-Barona and López 2020). Our research continues this line of work, highlighting the role of institutions in tackling environmental issues through local interventions in Ecuador. To do so, it investigates the contribution of biophysical and institutional factors to the effectiveness of water and forest management in the rural sections of the study area. Biophysical characteristics of forests and water resources, institutional complexity of management initiatives and institutional capacity of local governments are used to explain effectiveness. This is complemented with the analysis of spatial autocorrelation of the effectiveness to grasp insights from the spatial dynamics of the water and forest management effectiveness.

Ecuador was an early adopter of SDGs as an umbrella for its public policies, and local governments started incorporating them into their local development plans as early as 2016, which makes it a good candidate for studying the joint implementation of Agenda 2030. Additional work on the issue of decentralization of natural resources management in the context of Agenda 2030 and SDGs is vital for at least two reasons. First, measuring and reporting the existing levels of engagement with SDGs can inform strategies to assist local governments and their partners in designing and implementing better interventions. Additionally, agencies in charge of institutionalizing Agenda 2030 at the national level require independent assessments of the conditions that help local governments achieve their desired environmental outcomes to design appropriate support mechanisms.

The article continues with the presentation of a conceptual background for the study of decentralization of natural resources management in the context of the post2015 development agenda, including topics of institutional capacity and complexity as well as spatial interactions. After this, the section on materials and methods is presented. It contains a description of the study area, variables along with the regression and spatial methods. The next section presents the results which are followed by a discussion section where the findings are contextualized. The last section of the article offers general insights regarding the localization of SDGs and future research related to this issue.

\section{CONCEPTUAL BACKGROUND}

The idea that local government enjoys a privileged position to facilitate the mobilization of local development stakeholders for promoting inclusive sustainable development within their respective localities, is far from new. Decades of studies of decentralization policies highlight the need for local governments to develop the capacity to localize policies to effectuate change towards sustainability (Reddy 2016). Decentralization efforts have occurred in several waves, but most recently, they have been identified with the promotion of efficiency and the enhancement of public services, as well as with support for more open and accountable forms of government (Larson and Ribot 2004). Regarding environmental decentralization processes, previous research shows that they often occurred too hastily, reducing the potential of decentralization to produce more democratic and accountable institutions (Ribot, Agrawal and Larson 2006). For over three decades, governments have adopted decentralization policies to put the management of environmental resources closer to those directly impacted by them. Strategies for the devolution of responsibilities have varied from deconcentration of national agencies to the transfer of competencies to the lower levels of government or sectoral authorities. In some contexts, resources have been privatized (Wilder and Romero Lankao 2006) seeking to improve environmental outcomes. The move towards decentralization influences new interactions at the local level and creates new dynamics across scales that may or may not produce the desired results. Decentralization thus includes localization but it is not limited to it, as it also refers to the evolution of the interaction between different levels of government to deliver policy.

One particularly productive strand of the literature on decentralization that sheds light on the localization of SDGs is inspired by the works of Elinor Ostrom and the Bloomington School of Political Economy regarding the management of shared resources (e.g., infrastructure, common-pool resources). This study highlights the capacity of local actors to create local arrangements for managing resources. These arrangements, often informal collaborations between actors, are framed but not determined by the formal rules and norms of decentralization or other policies. The abundant literature produced by and after Elinor Ostrom highlights that local arrangements emerge in response to the characteristics of the resources under management (e.g., forests or water), the interaction of the actors governed by institutions and, in the context of environmental decentralization, the capacity of local governments to implement policy (Anderies and Jansen 2013).

The characteristics of the resources largely determine the scope and demand for resources that the implementation of public interventions will have. Given the very large difference among settings, actors tailor rules to diverse combinations of biophysical attributes, such as the size of the resource or the mobility of its resource units (e.g., water or trees). Therefore, as Ostrom (2005) suggests, analysts should not assume uniformity across all situations within a country. In particular, the relative size of a resource may bring more actors together, require that interventions generate more or larger behavioral changes and demand more resources for monitoring and management.

Sustaining the resources shared by urban and rural areas is a challenging task, and not one form of governance is fit for achieving this goal (Kooiman 2003; Young 2003). In reality, a wide range of actors, including local governments, not-profit organizations and local communities interact in complex social networks that define the rules and norms or institutions by which they use shared resources (Rydin and Falleth 2006; Bodin and Prell 2011; Henry and Vollan 2014). We follow the broad definition of institutions as the prescriptions that humans use to organize all forms of repetitive and structured interactions (Anderies and Janssen 2013).

The influence of institutions on policy outcomes depends largely on how actors define the appropriateness of the rules and norms in the face of specific environmental challenges along with how they use them (Ostrom 2008). Batterbury and Fernando (2006) argue that new governance regimes (e.g., the decentralization model 
adopted in Ecuador in 2008) alter the capabilities of state and civil society actors in ways that are often at odds with the legal prescriptions enshrined in law or in management policy that mandate collaboration across scales to produce desirable policy outcomes.

Therefore, the institutional complexity or institutional landscape in a given jurisdiction creates a variety of challenges for effectively allocating resources for public action. Complex governance arrangements often require the collaboration of an extended number of actors across multiple levels along with the definition and use of a large number of rules to tackle existing environmental challenges (Berardo and Lubell 2016). Local governments may participate in such arrangements even when the institutional capacities they have are limited. Some will join as free riders, letting partners do what they are not capable of or willing to do. Others will join to monitor the behavior of their peers to make strategic decisions about their engagement with natural resources management (Ostrom 2005). In sum, a large number of actors and rules increases the complexity of collaborative arrangements because they require more resources to produce and sustain collective action, and often there is competition among groups of actors for the provision of one public good or service (Ostrom 2008; 2005), such as when different levels of government share competencies over a policy issue.

The institutional capacity of local governments to implement their assigned competencies is critical to achieving the desired policy outcomes. In his literature review on municipal performance in forest management, Andersson (2003) shows that institutional capacity is one of the main factors explaining the production of desirable management outcomes. The literature on environmental decentralization shows that institutional capacity is of particular importance for natural resource governance (de Oliveira 2002; Andersson and Ostrom 2008; Fiszbein 1997). This paper follows Fiszbein's (1997) definition of local capacity as the existence of the government tools in the areas of labor, capital and technology. Local governments need financial resources, qualified personnel and the ability to organize their internal affairs, as well as to engage with other actors. Institutional capacity is of particular importance for the localization of SDGs or the translation of global, regional, and national objectives into contextappropriate interventions (Wymann von Dach et al. 2018). In the context of the previous conceptual background, it can be concluded that the biophysical characteristics of the natural resources, governance arrangements and institutional capacity of local governments are associated with policy outcomes that subsequently represent the success or failure of SDG implementation. One challenge is how to account for these policy outcomes when there are no detailed and official indicators or statistics available, especially in rural areas. The perceived effectiveness has been proved to adequately represent the management of nature-related phenomena at a local level (Pradhan et al. 2017) and to be associated with social behaviour, policy implementation and use of natural resources (Pradhan et al. 2017; Wan, Shen and Yu 2014). In this context, the perceived effectiveness of forest and water management is assessed considering the characteristics of their respective natural resources, the complexity of governance arrangements and the institutional capacity of local governments. The perceived effectiveness was identified from the elected officials of local governments.

Local governments do not face the dynamics of localization in a vacuum. In principle, they develop patterns of interactions due to shared (interpretations of) problems that relate to the spatial distribution of natural resources as well as the resources needed to formulate and implement policies. Zuindeau (2006) argues for using a spatial approach to understand the challenges related to sustainable development, in particular those arising between the logics of sustainability and competitiveness. Thus, the effectiveness of SDG-related actions also has spatial implications because the satisfactory performance of some policy-oriented actions in one territory may lead to their adoption in the neighbouring jurisdictions with similar problems (Nicholson-Crotty and Carley 2016). As Cook, An, and Favero (2018) argue, spatial analysis of policy implementation highlights interdependencies between jurisdictions that will contribute to alleviating problems such as increasing rates of deforestation or poor water management practices. For this reason, studying the spatial distribution of the perceived effectiveness of water and forest management and evaluating interdependencies (that can be identified by spatial autocorrelation) between areas where this effectiveness is expressed are crucial approaches for a better understanding of the natural resources management in the local governments of the study area.

\section{MATERIALS AND METHODS}

Our study site is located in the rural zone of a metropolitan area in Ecuador. Ecuador is one of the most biodiverse countries in the World (Myers et al. 2000; Bass et al. 2010) as 20\% of its landmass territory is composed of protected areas that include diverse forests and watersheds (Cuesta et al. 2017). This study was carried out in the rural parishes of the Metropolitan District of Quito (MDQ), a District that includes the capital city of Quito. The MDQ encompasses 32 urban parishes and 33 rural parishes which are the lowest level of government in the country. According to the last Ecuadorian Population and Housing Census, the MDQ had 2.2. million inhabitants (INEC 2010). For 2020, the projected MDQ population is 2.7 million (INEC 2020). The MDQ houses around 20 percent of Ecuador's urban population in the city of Quito (located at 2850 meters above sea level, m.a.s.l), a city with political, financial and symbolic resources to distinctively respond to SDGs compared to the rest of the country (Horn and Grugel 2018). The urban parishes that form the city of Quito (see Figure 1) are managed by an elected Mayor and a City Council. On the other hand, residents of the rural parishes elect a local government (Juntas Parroquiales) with competencies that occasionally overlap with those of the city of Quito, the province of Pichincha and the national government.

The MDQ has an area of 4231 square kilometers with $54 \%$ of it covered by forests and other natural areas. The ecosystems of the District are diverse as they are influenced by the altitudinal variations, from the valleys (2500 m.a.s.l) located at the east of the city of Quito, to the Pichincha volcano complex (4794 m.a.s.I.) located at the west of the city, including the tropical forests (around 1200 m.a.s.l.) located in the northwest of the District. The MDQ contains several river basins and other bodies of water, some of its main rivers are San Pedro, Pita, Machángara, Guayllabamba and Mindo, located mostly in the rural parishes.

Local initiatives for water and forest management are shaped by the history of environmental decentralization in Ecuador. In the late 1990s, the fragmentation of the political system reinforced bottom-up demands 
for decentralization and forced the transference of competencies from the Ecuadorian Ministry of the environment to other sectors and levels of government even before the national authority had consolidated as such. This reduced the capacity of both the national and local authorities to perform their assigned roles (Faust et al. 2008). Between the years 2000 and 2008, when the new decentralization regulations were approved as part of a new constitution, Ecuador lived a period of decentralization á la carte (Bedón Tamayo and Guerra Terán 2012). Each local government requested additional competencies creating a complex system for the transfer of financial resources. The aim of the decentralization policy was that deepening decentralization should set a configuration of public interventions where local governments have an important role in making decisions and implementing policies with their allies.

Considering this context, it is crucial to determine what local governments are doing to localize SDGs and how successful their initiatives are according to their particular characteristics.

To document the SDG-related initiatives undertaken by local governments and their partners as well as their outcomes, we used a standardized survey questionnaire divided into three sections. The first section gathered information about a wide array of policy initiatives in which local governments participate, including environmental issues. This section also provided information about the public, private and social actors involved in the implementation of these initiatives. The second section gathered information on the perceived effectiveness of the actions identified in section 1. We were able to apply the questionnaire in 31 of 33 rural parishes ( $n=$ 31). Respondents evaluated the achieved effectiveness of each policy issue on a 3-point Likert scale. In all cases, the respondent was the president of the parish and completion of the survey took about 1 hour and 10 minutes on average. All parish presidents had been in office for an average of 8 years before participating in the study, which provides them with enough knowledge on the issues of interest. The third section gathered information about the existing institutional capacities of the local government to implement those initiatives.

Policy effectiveness is the dependent variable in this study. Given that objective measures of policy effectiveness are often unavailable in developing countries (Geddes 1994; Eakin and Lemos 2006) we conducted this study using the perception of policy effectiveness as a proxy. The perceived effectiveness of public activity towards SDGs was defined as the extent to which public interventions are producing the desired management outcomes according to those

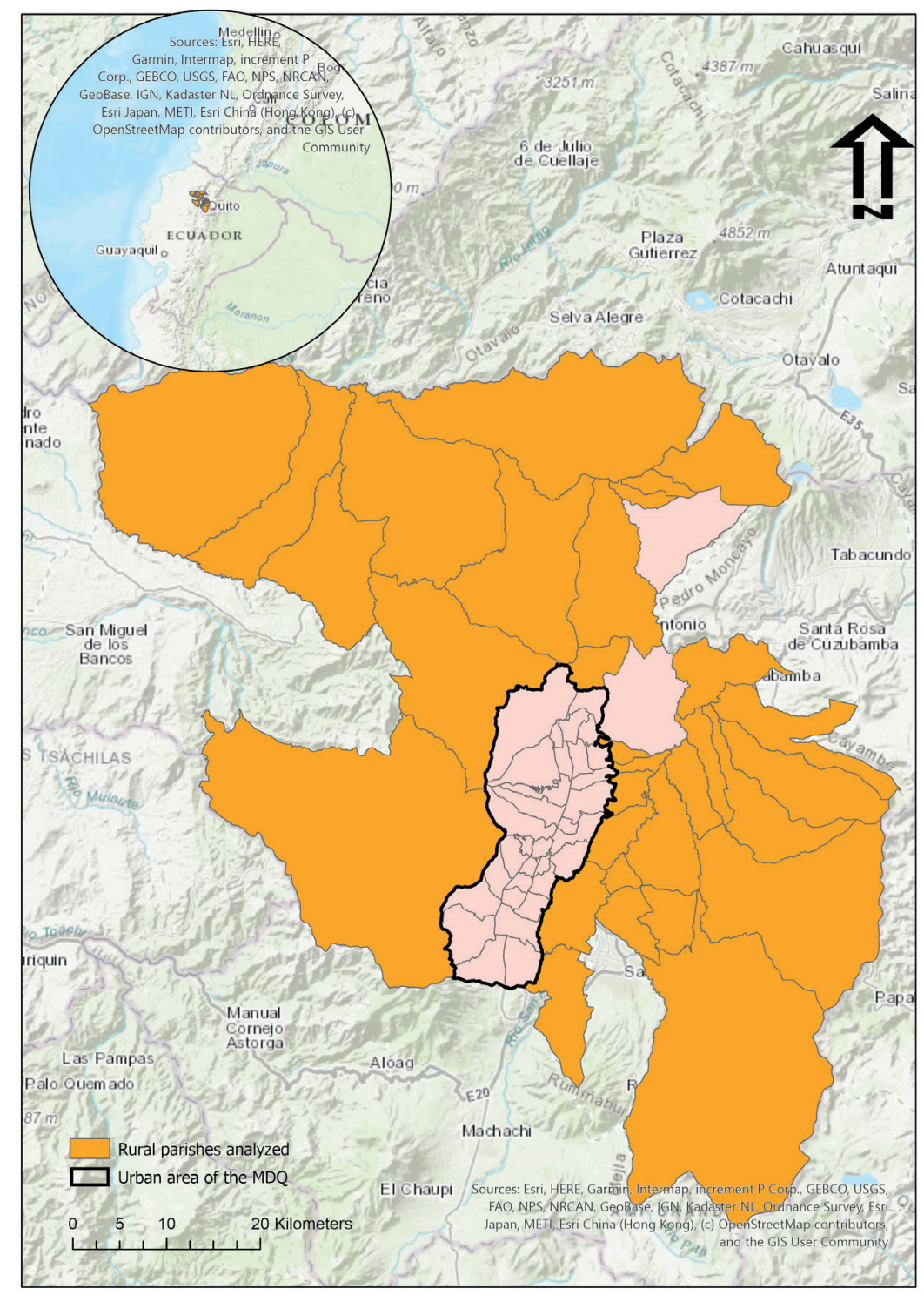

Fig. 1. Study area

Source: the authors. Study area generated based on geoinformation provided by the open-access database of the Municipality of the Metropolitan District of Quito 
promoting them. We used the acronym EFFO to refer to the perceived effectiveness of policies related to forest issues and EFWA for the perceived effectiveness of water policies. Policy initiatives related to each natural resource tackle several subdimensions. Our survey shows that, for the case of forests, rural parishes work on forest conservation, controlling the expansion of the agricultural frontier and forest-fire prevention. For the case of water, rural parishes work on increasing access to drinking water and sanitation and managing the growth in water-demand.

The first independent variable relates to the characteristics of the biophysical context where local governments and their allies intervene. The percentage of the forested regions (WOFO) and the number of drains per capita (WA3) were used for each parish as a proxy to the biophysical characteristics. WOFO was calculated using the land use map of the Metropolitan District of Quito and WA3 was calculated using open-access information provided by the Municipality of Quito. The assumption is that jurisdictions with extensive forested areas or more natural drains may face more significant management challenges.

The second independent variable is institutional complexity which we study by measuring the number of stakeholders involved for each resource, namely forests (GOFO) and water (GOWA). Each one of these resources is managed through institutions that are put in place by many actors in several venues according to specific rules and norms. In the MDQ, these venues include local decision-making venues as well as cross-scale initiatives. We used the count of actors participating in the management of each environmental component as a proxy to institutional complexity because our data shows that the number of actors correlates perfectly with the number of venues.

The third independent variable is the institutional capacity of the rural parishes. To measure this variable, we used a score of the number of areas with weak capacity (CA) in each rural parish reported by the parish president. This score was constructed using dummy variables representing the lack of institutional capacity across five domains: administration, finance, planning, project design and implementation, and social participation. The higher is the score, the weaker is the institutional capacity of the local government.

Since EFFO and EFWA are ordinal variables, ordinal logistic regressions were applied applied to evaluate how the independent variables influence the scores of perceived effectiveness. Considering the number of parishes studied ( $n=31$ ), and the three predictors used, the statistical power of the performed regression was higher than 0.8 (large effect size, $a=0.05$, two tails).
Additionally, using bivariate analysis, the relationships between the effectiveness and the independent variables was assessed to explore how will each independent variable in isolation explain EFFO and EFWA.

Others have used geospatial information extracted from remote sensing to measure the implementation of SDG 15 in China (Liu, Bai and Chen 2019). However, there is little spatial analysis applied to SDGs-related policy actions based on subjective measures. In this context, spatial lag regressions were calculated to assess whether spatial dependencies of perceived effectiveness exist, which would mean that spatial distribution of rural parishes influences the perception of effectiveness measured across them. The assumption is that neighboring parishes should exhibit similar levels of perceived effectiveness because they are more likely to share problems than nonneighboring ones (e.g., forest fires or increasing water demand). The Getis-Ord Gi* statistic was also applied to identify hotspots and coldspots of perceived effectiveness of policy implementation in the rural parishes. The $\mathrm{Gi}^{*}$ statistic identifies entities (parishes) with high values of perceived effectiveness that are surrounded by other parishes with high values of perceived effectiveness. Finally, the Anselin Local Moran's I was calculated to identify spatial clusters and outliers for perceived effectiveness.

\section{RESULTS}

As expected from the literature, we found a diversity of actors involved in the implementation of SDG-related initiatives in each rural parish of the MDQ. The number of actors reported as partners of rural parishes is 13 on average. These actors include public sector organizations from other levels of government, as well as nongovernmental actors such as grassroots organizations and private companies. Also, regarding institutional capacity, a mode of 3 was found and the closer this variable is to 5 , which is the number of institutional areas evaluated, the lower is the capacity. Table 1 shows the results of the ordinal logistic regressions that associate institutional capacity and complexity, as well as the characteristics of forests and water with perceived effectiveness.

In the case of the regression with the perceived effectiveness water, with of forest management as the dependent variable, only the number of stakeholders involved (GOFO) was found to be significant. For the perceived effectiveness of water management as the dependent variable, the number of stakeholders involved (GOWA) was also found significant. The pseudo $\mathrm{R}^{2}$ indicates that the calculated EFFO and EFWA models may explain $21 \%$ and $31 \%$ of the variance of perceived effectiveness, respectively. In the EFFO model, the significance level of the test of parallel lines (TPL) shows the existence of the same slope coefficients across response categories.

Table 1. Ordinal logistic regression results

\begin{tabular}{|c|c|c|c|}
\hline EFFO & Covariates & Estimates & Significance \\
\hline Pseudo R2: 0.210 & CA & -0.048 & 0.867 \\
\hline TPL: 0.200 & GOFO & 0.302 & 0.003 \\
\hline & WOFO & 0.003 & 0.763 \\
\hline EFWA & & & \\
\hline Pseudo R2: 0.310 & CA & -0.464 & 0.130 \\
\hline TPL: 0.000 & GOWA & 0.272 & 0.027 \\
\hline & WA3 & 5,923 & 0,174 \\
\hline
\end{tabular}

Source: the authors 
Table 2 shows the results of several ordinal logistic regressions that consider only one independent variable. GOFO was again identified as a significant predictor of EFFO, but in the case of EFWA model, the covariates CA and GOWA show to be significant predictors of EFWA (95\% and 99\% confidence level, respectively). GOFO may explain $21 \%$ of the variance of EFFO. CA may explain $12 \%$ of the variance of EFWA, while GOWA may explain 20\% of EFWA's variance.

Table 3 shows the results of the performed spatial lag regressions. In the case of the regression with the perceived effectiveness of forest management as the dependent variable, the number of stakeholders (GOFO) is significant, mirroring the result obtained in the ordinal regression. The $R^{2}$ indicates that the calculated model may explain $28 \%$ of the variance of perceived effectiveness. The additional covariate obtained in this regression, EFFO-S, which represents the spatial dependency of perceived effectiveness, is not significant, which suggests that there is no influence on the observations of perceived effectiveness by neighboring observations. The Breusch-Pagan (BP) test of significance indicates that the assumption of homoscedasticity is accomplished for the model. The Likelihood Ratio (LR) test of significance confirms that the dependent variable does not have spatial effects.

In the case of the regression with the perceived effectiveness of water management as the dependent variable, the number of stakeholders (GOWA) is also significant, as it was in the results obtained for the ordinal regression. In this case, the $\mathrm{R}^{2}$ indicates that the calculated model may explain $28 \%$ of the variance of the perceived effectiveness. The additional covariate obtained in this regression, EFWA-S, representing the spatial dependency of perceived effectiveness was not significant, which suggests that there is no influence on perceived effectiveness observations by neighboring observations. The significance results for the BreuschPagan (BP) test and the Likelihood Ratio (LR) test indicate the homoscedasticity condition and the absence of spatial effects, respectively.

Figure 2 shows the results of the $\mathrm{Gi}^{*}$ statistic. Hotspots for the perceived effectiveness of forest management were identified in two western rural parishes of the Metropolitan District of Quito, while significant coldspots appear in some eastern rural parishes (Figure $2 a)$. In the case of the perceived effectiveness of water management, only coldspots were found in two eastern rural parishes (Figure 2b).

Figure $3 a$ presents the results of the Anselin Local Moran's I, which identifies spatial clusters and outliers at $95 \%$ of confidence. This measure defined a northern parish as a cluster of high perceived effectiveness of forest management. On the other hand, clusters of low perceived effectiveness of forest management were identified in eastern parishes. One eastern parish was identified as an outlier in terms of forest management; that is a parish with high perceived effectiveness of forest management surrounded by parishes with low effectiveness. In Figure 3b, the Anselin Local Moran's I identified one low-high outlier (low EFWA surrounded by parishes with high EFWAs) in a northern parish, and two high-low outliers (high EFWA surrounded by parishes with low EFWA).

\section{DISCUSSION}

This study is a contribution to the ongoing discussion on the localization of Agenda 2030 and SDGs in developing countries framed under the larger discussions of environmental decentralization. The focus of this paper is on how biophysical and institutional variables explain the local-based perception of the effectiveness of

Table 2. Ordinal logistic regression results considering only one independent variable

\begin{tabular}{|c|c|c|}
\hline EFFO & Estimate & Significance \\
\hline Model with only CA as covariate Pseudo R2: 0.01 & 0.142 & 0.610 \\
\hline Model with only GOFO as a covariate Pseudo R²: 0.21 & 0.290 & 0.003 \\
\hline Model with only WOFO as a covariate Pseudo R2: 0.00 & 0.000 & 0.997 \\
\hline \multicolumn{3}{|l|}{ EFWA } \\
\hline Model with only CA as a covariate Pseudo R²: 0.12 & -0.634 & 0.034 \\
\hline Model with only GOWA as a covariate Pseudo R²: 0.20 & 0.336 & 0.008 \\
\hline Model with the only WA3 as a covariate Pseudo R2: 0.12 & 7.997 & 0.063 \\
\hline
\end{tabular}

Source: the authors

Table 3. Spatial lag regression

\begin{tabular}{|c|c|c|c|}
\hline EFFO & Covariates & Coefficients & Significance \\
\hline$R^{2}: 0.280$ & CA & 0.154 & 0.631 \\
\hline BP: 0.123 & GOFO & 0.215 & 0.021 \\
\hline LR: 0.131 & WOFO & 0.003 & 0.781 \\
\hline & EFFO-S & 0.294 & 0.125 \\
\hline EFWA & & & 0.611 \\
\hline R': 0.280 & CA & -0.188 & 0.007 \\
\hline BP: 0.323 & GOWA & 0.346 & 0.593 \\
\hline LR: 0.345 & WA3 & 2.533 & 0.302 \\
\hline
\end{tabular}

Source: the authors 

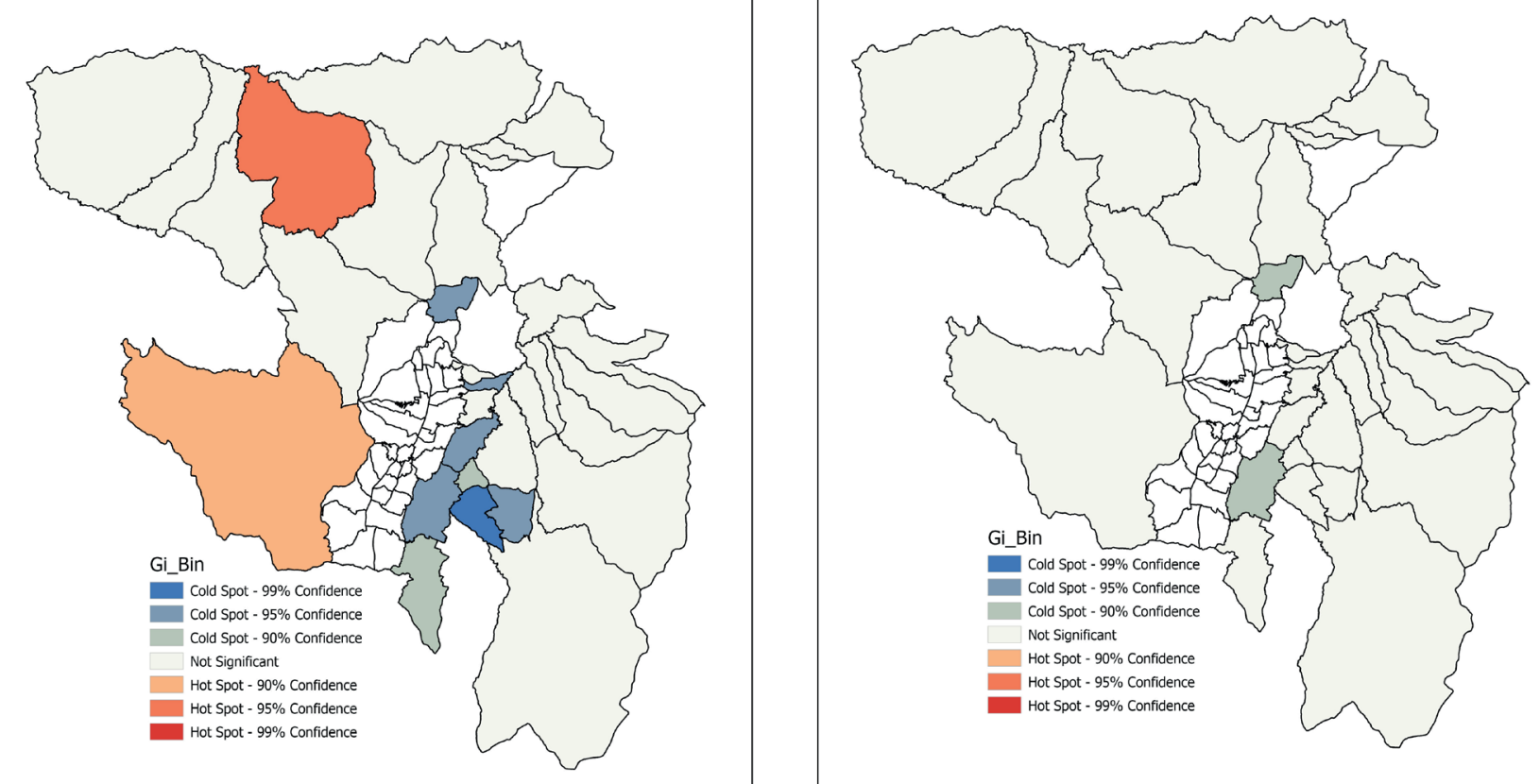

Fig. 2. Results of $\mathrm{Gi}^{*}$ statistic for (a) Perceived effectiveness of forest management; (b) Perceived effectiveness of water management

Source: the authors
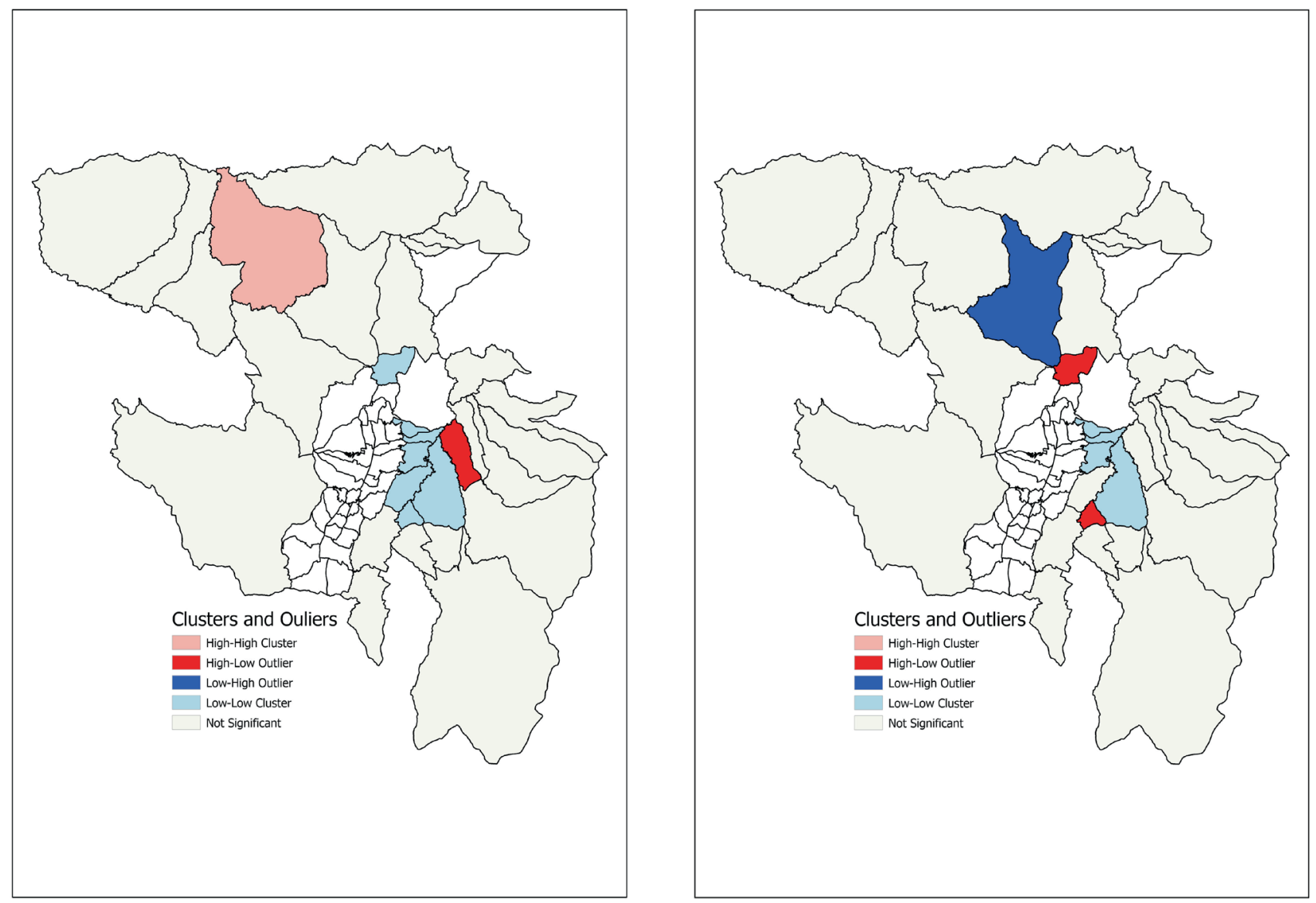

Fig. 3. Results of Anselin Local Moran's I for (a) Perceived effectiveness of forest management; (b) Perceived effectiveness of water management

Source: the authors 
environmental management related to forests and water. The originality of the approach lies in the fact that we linked subjective measures of policymaking (institutional capacity and institutional complexity) with objective measures of water and forest resources (percentage of the forested regions and number of drains per capita) and performed statistical and spatial analyses to understand the outcomes of public interventions (effectiveness of the water and forest management). To our knowledge, this is the first study to deal with the objective-subjective and spatial issues of SDGs in Latin America.

The regression analysis of the survey data showed no significant relationship between the characteristics of the natural resources of interest (forests and water) and the perceived effectiveness of the management of these resources. This is surprising considering the striking differences in forested areas and the number of drainages across rural parishes.

However, the most striking result from our analyses is the lack of significance of the local government's capacity as a predictor of perceived effectiveness for both forest and water management. In other words, the ability to organize their internal affairs, to plan and bring local actors into implementing SDG-related actions does not seem to affect the effectiveness of forest and water management. One possible explanation for this finding relates to the fact that despite their differences, rural parishes still have very limited resources to design and implement SDG-related initiatives. The Ecuadorian legislation allows governments of urban municipalities to use a wide array of tools to collect revenue but makes rural parishes dependent on transfers from the central government (Díaz-Cassou and Viscarra Andrade 2017; Dávila, Villares and Placencia 2018). During fieldwork, respondents offered anecdotal evidence that these transfers were, in most cases, only sufficient to cover the salaries of a very basic staff. For this reason, most of their work is related to facilitating interactions of other actors in their jurisdiction. Our findings suggest that instead of being the main actors in the localization of SDGs, rural parishes may be only responding to initiatives headed by other actors. Only in the bivariate analysis of water management, the capacity of the local governments was found to be significant. This suggests that some interaction effects between variables could be at play and also that capacity is more important for water than forest management, given that in this context, water management usually requires to maintain higher levels of capital spending.

The significance of the institutional complexity studied using the number of stakeholders involved in forest and water management (GOFO and GOWA) matches findings from previous research that identifies social actors and their activities as drivers of water governance regimes (Wiek and Larson 2012). This body of research suggests that hydro-social cycles are inherently political, historical and cultural (Wiegleb and Bruns 2018). Our findings should be interpreted considering what we now know about institutional capacity. Parishes interact with several actors for the localization of public interventions towards SDGs and, as the number of actors increases, the perception of effectiveness also increases. This significant relationship could be the consequence of officials in local governments getting the feeling that things are getting done while instead, much time is spent organizing and facilitating repeated interactions. This phenomenon has been described by Leach and Sabatier (2005) as the 'halo effect' and explains why the overall perception of effectiveness is high across parishes regardless of the forested area and the density of drainages, as well as the self-reported institutional capacity. However, this upward bias in the perception of environmental improvement should be tested empirically using objective data.

The spatial analysis shows that the perception of effectiveness by neighboring authorities do not influence each other. This finding is indicative of the possible lack of interactions among the local authorities of parishes, which is a problem from the localization perspective because shared problems are better tackled by joint initiatives. Moreover, this finding adds credibility to the idea that some 'halo effect' is at play. If actors objectively share problems, such as forest fires and water scarcity, but they perceive that management is effective despite their lack of interactions, something is skewing that perception.

Additionally, this finding supports the idea that actors at other levels of government draw parishes towards interventions related to SDGs. However, this is not necessarily a problem for localization given that its idea is that local government involvement exists in a significative manner rather than local governments leading all processes. Nevertheless, this finding strengthens our doubts about the appropriateness of the policy initiatives in terms of solving local problems due to the skewed perception of policy effectiveness.

On the other hand, scale effects may also affect the non-spatial dependency of the perceived effectiveness variable at the parish level. Moreover, other relationships among local stakeholders (at village or neighborhood level) may present spatial autocorrelation of perceived effectiveness. Further research will be required to explore spatial tendencies of the dependent variable at different scales.

The spatial analysis found hotspots as well as coldspots of perceived effectiveness for both forests and water. The distribution of these spots can be explained by the pattern of the urban frontier expansion. In our fieldwork, this phenomenon was identified as one of the most common concerns among presidents of rural parishes. The city of Quito and its conurbations are expanding aggressively towards the eastern parishes reducing their capacity to manage the remnants of existing forested lands. The rules and norms that govern the interactions between rural parishes and the metropolitan government explain this phenomenon. Although rural parishes define a local development plan that includes the management of the natural environment in their jurisdiction, the metropolitan government of Quito is in charge of granting all building permits. For instance, the eastern parish of Cumbayá is administratively considered a rural parish. Still, in reality, this parish is practically urban given its low percentage of nonurban land-use. It constitutes one of the most attractive areas for urban development due to its proximity to the new international airport. Therefore, it is not surprising that in this parish and its neighboring parishes (Figure 2a) coldspots of perceived effectiveness in forest management were identified. In other words, the most urbanized rural parishes report less effective forest management.

On the other hand, the two western rural parishes of Lloa and Nanegal are the hotspots of perceived effectiveness in forest management. These parishes have large areas of subtropical forests and lay beyond the current urban expansion of Quito. Nanegal was also identified as a cluster of high perceived effectiveness in forest management (Figure 3a). This parish sits within an area where private and community forest reserves have been created in the past two decades. In addition, our data show that a great diversity of actors takes part in the implementation of interventions in this area which also suggests the presence of a halo effect. 
Additionally, the eastern rural parish of Puembo was identified as a spatial outlier in terms of forest management. Several states belonging to high-income residents and agro-industrial companies are located in this rural parish. The land is often occupied by forest plantations with exotic species, especially eucalyptus. This may influence the perception of the high effectiveness of forest management compared to their neighbors. However, the composition of property ownership suggests that fewer interactions among actors are present in this parish in comparison with their more populated neighbors.

In terms of water, Figure $2 \mathrm{~b}$ shows significant low levels of perceived effectiveness of water management in two parishes, Pomasqui and Conocoto. This situation is also related to the pattern of the city expansion. In the past two decades, the urban sprawl has been relentless in those areas. However, this growth is qualitatively different from that of some eastern parishes such as Cumbayá, as it is mainly devoted to tackling demand from lower socioeconomic groups, which involves a more significant number of developers, some of them informal, and fewer resources to protect the water streams.

The cluster analysis shows that the northern parish of Calacali is a territory with low perceived effectiveness of water management surrounded by parishes with high perceived effectiveness (Figure $3 \mathrm{~b}$ ). Calacali is the northern rural parish with relatively dry weather and a low density of drains compared with their most tropical parochial neighbors such as Nanegal. We could assume that the local authorities and stakeholders in Calacali may have little incentives for managing water bodies due to its low population density and water resource characteristics.

On the other hand, two parishes, Pomasqui and Guangopolo, were found to be high-low outliers in water management, meaning that authorities in these parishes report higher perceived effectiveness compared to their neighbors. Both parishes have experienced continuous urbanization in the last 20 years and rank among the most densely populated in the sample. Therefore, urban residents and the recent economic development of both areas with a highway connecting them to the city may be offering political incentives for local authorities to manage water resources or at least to interact frequently with other actors, creating the 'halo effect'.

Finally, institutional complexity expressed in the number of stakeholders is influential for the management of forests and water in the rural parishes. However, this finding does not imply that an effective and permanent network of stakeholders oriented towards the implementation of SDGs exists. On the contrary, our study shows that institutional complexity plays a role in how local governments implement SDG-related actions. In particular, the way intergovernmental interactions are designed and executed is still constraining the participation of the lowest levels for the government. Moreover, the spatial regression analysis suggested a lack of communication between the lowest levels of government despite their shared environmental problems and the need to complement each other's lack of institutional capacity.

The lack of policy coherence highlighted by the different priorities of the city and the parish governments suggests that although some mechanisms of citizen participation have been implemented in the $\mathrm{MDQ}$, there are several challenges for proper participatory governance, such as patronage practices embedded in hierarchical structures and corporate management models (Córdova 2011).

\section{CONCLUSIONS}

The localization of Agenda 2030 and its 17 SDGs relies on the participation of the levels of government that are closer to the people to formulate and implement actions in ways that are relevant to the context. However, the involvement of local governments needs a nurturing environment, one that provides resources and helps to close the gaps in institutional capacity. Localization needs to be supported by decentralization policies that create the conditions to achieve it. Our approach to the study of the effectiveness of SDG-related actions in the rural area of the Metropolitan District of Quito shows what happens when such an environment is not nurturing but harming. In this case, the presence of certain types of interactions across different levels of government and among actors are isolating the rural parishes from each other and creating a 'halo effect'.

Better strategies are required to ensure that the participation of local governments in policy implementation is meaningful. Joint evaluation of shared problems could help authorities in charge of the implementation of Agenda 2030 to have more assessment of the outcomes of the localization of interventions. Indeed, it is increasing the diversity of interactions that may help actors have a better understanding of the state of natural resources in their jurisdictions.

Future studies should look into whether different objective measures of environmental interventions could influence perceived effectiveness in other ways. In this case, the scale of the analysis did not allow us to determine more detailed characteristics of the SDGs-related interventions. Some communities in the rural parishes may have specific governance configurations than those reported by parish authorities. Additionally, continuing research into spatial methods to produce and assess SDGs indicators appears fully justified because of the implications of geo-located SDGs actions and achievements for decision making and planning, especially at the local level. In this sense, spatial analysis needs to incorporate qualitative measures beyond the traditional GIS-based indicators in order to understand SDG localization from a more comprehensive and pluralistic perspective.

\section{REFERENCES}

Anderies John M. and Marco A. Janssen (2013). Sustaining the Commons. Tempe: Center for the Study of Institutional Diversity. Arizona State University. https://sustainingthecommons.org/.

Andersson Krister (2003). What Motivates Municipal Governments? Uncovering the Institutional Incentives for Municipal Governance of Forest Resources in Bolivia. The Journal of Environment \& Development 12 (1), 5-27. http://jed.sagepub.com/cgi/doi/10.1177/1070496502250435.

Andersson Krister P. and Elinor Ostrom (2008). Analyzing Decentralized Resource Regimes from a Polycentric Perspective. Policy Sciences 41 (1), 71-93. http://link.springer.com/10.1007/s11077-007-9055-6.

Bass Margot S., Matt Finer, Clinton N. Jenkins, Holger Kreft, Diego F. Cisneros-Heredia, Shawn F. McCracken, Nigel C. A Pitman, et al. (2010). Global Conservation Significance of Ecuador's Yasuní National Park. P, DOl: 10.1371/journal.pone.0008767

Batterbury Simon P.J. and Jude L. Fernando (2006). Rescaling Governance and the Impacts of Political and Environmental Decentralization: An Introduction. World Development 34 (11) 1851-63. https://inkinghub.elsevier.com/retrieve/pii/S0305750X0600129X.

Bedón Tamayo, Gustavo Adolfo and Germán Roberto Guerra Terán (2012). Nuevo Modelo de Descentralización En El Ecuador a Partir de La

Constitución Del 2008. In XVII Congreso Internacional Del CLAD Sobre La Reforma Del Estado y de La ADministarción Pública, 1-19. Cartagena. 
Belay Mehretie and Woldeamlak Bewket (2015). Enhancing Rural Livelihoods through Sustainable Land and Water Management in Northwest

Ethiopia. Geography, Environment, Sustainability 8(2), 79-100.

Berardo Ramiro and Mark Lubell (2016). Understanding What Shapes a Polycentric Governance System. Public Administration Review 76(5),

738-51., DOl: 10.1111/puar.12532.

Bodin Örjan and Christina Prell, eds. (2011). Social Networks and Natural Resource Management. Uncovering the Social Fabric of Environmental

Governance. Cambridge: Cambridge University Press.

Cisneros Paul, Pablo Cabrera-Barona and Víctor López (2020). Civil Society and the 2030 Agenda. An Assessment of the Implementation of SDG-

Actions in the Metropolitan District of Quito. Iberoamerican Journal of Development Studies 9(1)., DOI: 10.26754/ojs_ried/ijds.431

Cook Scott J. Seung-Ho An and Nathan Favero (2018). Beyond Policy Diffusion: Spatial Econometric Models of Public Administration. Journal of

Public Administration Research and Theory 29(4): 591-608., DOl: 10.1093/jopart/muy050

Córdova Marco. (2011). Quito: Gobernanza Metropolitana e Innovación Territorial En El Nuevo Milenio. In Quito: Un Escenario de Innovación,

edited by Fernando Carrión and Manuel Dammert, 133-67. Quito: MDMQ, OLACCHI. (in Spanish)

Cuesta Francisco, Manuel Peralvo, Andrés Merino-Viteri, Macarena Bustamante, Francis Baquero, Juan F. Freile, Priscilla Muriel and

Omar Torres-Carvajal. (2017). Priority Areas for Biodiversity Conservation in Mainland Ecuador. Neotropical Biodiversity 3(1), 93-106.,

DOI: 10.1080/23766808.2017.1295705

Dávila María José, Gustavo Villares and Marcelo Placencia (2018). Recursos Financieros de Los Gobiernos Autónomos Descentralizados: Caso de

Estudio Gobiernos Autónomos Descentralizados Municipales. Economía y Negocios 9(2), 65-82. (in Spanish)

Díaz-Cassou Javier and Hernán Viscarra Andrade (2017). La Brecha Fiscal Horizontal En Ecuador y Su Igualación. BID. https://publications.iadb.

org/publications/spanish/document/La-brecha-fiscal-horizontal-en-Ecuador-y-su-igualación.pdf.

Eakin Hallie and Maria Carmen Lemos (2006). Adaptation and the State: Latin America and the Challenge of Capacity-Building under

Globalization. Global Environmental Change 16(1), 7-18. http://linkinghub.elsevier.com/retrieve/pii/S0959378005000713.

Faust Jörg, Florian Arneth, Nicolaus von der Goltz, Imke Harbers, Judith Illerhues and Michael Scholms, (2008). Political Fragmentation,

Decentralization and Development Cooperation: Ecuador in the Latin American Context. Ecuador in the Latin American Context. Bonn: German

Development Institute.

Fiszbein Ariel (1997). The Emergence of Local Capacity: Lessons From Colombia. World Development 25(7), 1029-43.

Geddes Barbara (1994). Politician's Dilemma. Building State Capacity in Latin America. Berkeley: University of California Press.

Henry Adam Douglas and Björn Vollan (2014). Networks and the Challenge of Sustainable Development. Annual Review of Environment and

Resources 39(1), 583-610.

Horn Philipp and Jean Grugel (2018). The SDGs in Middle-Income Countries: Setting or Serving Domestic Development Agendas? Evidence

from Ecuador. World Development 109, 73-84., DOl: 10.1016/j.worlddev.2018.04.005

INEC (2010). Censo de Población y Vivienda. https://www.ecuadorencifras.gob.ec/proyecciones-poblacionales/ (in Spanish)

INEC (2020) Proyecciones Poblacionales. Quito.

Kooiman J. (2003). Governing as Governance. London: SAGE Publications.

Larson Anne M. and Jesse C Ribot. (2004). Democratic Decentralisation through a Natural Resource Lens: An Introduction. The European Journal

of Development Research 16(1), 1-25., DOI: 10.1080/09578810410001688707.

Leach William D. and Paul A. Sabatier (2005). Are Trust and Social Capital the Keys to Success? Watershed Partnerships in California and

Washington. In Swimming Upstream, edited by Paul A Sabatier, Will Focht, Mark Lubell, Zev Trachtenberg, Arnold Vedlitz, and Marty Matlock, $233-58$.

Cambridge: The MIT Press.

Liu Shaoyang, Jianjun Bai and Jun Chen (2019). Measuring SDG 15 at the County Scale: Localization and Practice of SDGs Indicators Based on

Geospatial Information. ISPRS International Journal of Geo-Information 8(11)., DOI: 10.3390/ijgi8110515.

Myers Norman, Russell A. Mittermeier, Cristina G. Mittermeier, Gustavo A.B. da Fonseca and Jennifer Kent. (2000). Biodiversity Hotspots for

Conservation Priorities. Nature 403 (6772), 853-58., DOI: 10.1038/35002501

Nicholson-Crotty Sean and Sanya Carley (2016). Effectiveness, Implementation, and Policy Diffusion. State Politics \& Policy Quarterly 16 (1), 78 -

97., DOI: $10.1177 / 1532440015588764$

Okunola Akinbode Michael (2016). Nigeria: Positioning Rural Economy for Implementation of Sustainable Development Goals. Turkish Journal

of Agriculture - Food Science and Technology 4 (9), 752-57.

Oliveira José Antonio de (2002). Implementing Environmental Policies in Developing Countries Through Decentralization: The Case of Protected

Areas in Bahia, Brazil. World Development 30(10), 1713-36.

Ostrom, Elinor (2005). Understanding Institutional Diversity. Princeton University Press.

Ostrom Elinor ed. (2008) Governing the Commons. The Evolution of Institutions for Collective Action. Cambridge University Press.

Pradhan Neera Shrestha, Yao Fu, Liyun Zhang and Yongping Yang. (2017). Farmers' Perception of Effective Drought Policy Implementation: A

Case Study of 2009-2010 Drought in Yunnan Province, China. Land Use Policy 67, 48-56., DOl: 10.1016/j.landusepol.2017.04.051.

Reddy P.S. (2016). Localising the Sustainable Development Goals (SDGs). African Journal of Public Affairs 9 (2), 1-15.

Ribot Jesse C., Arun Agrawal and Anne M. Larson (2006). Recentralizing While Decentralizing: How National Governments Reappropriate Forest

Resources. World Development 34(11): 1864-86. https://linkinghub.elsevier.com/retrieve/pii/S0305750X06001306.

Rydin Yvonne and Eva Falleth, eds. (2006). Networks and Institutions in Natural Resource Management. Cheltenham: Edward Elgar.

Slack Lucy (2014). The Post-2015 Global Agenda -a Role for Local Government. Commonwealth Journal of Local Governance. https://epress.lib.

uts.edu.au/journals/index.php/cjlg/article/view/4069.

United Nations Development Programme (2014). Dialogue on 'Localising the Post-2015 Development Agenda'. Global Taskforce of Local and

Regional Governments for the Post-2015 Development Agenda Towards Habitat III. New York.

Wan Calvin, Geoffrey Qiping Shen and Ann Yu. (2014). The Role of Perceived Effectiveness of Policy Measures in Predicting Recycling Behaviour

in Hong Kong. Resources, Conservation and Recycling 83 (February), 141-51., DOl: 10.1016/j.resconrec.2013.12.009.

Wiegleb Viviana and Antje Bruns (2018). Hydro-Social Arrangements and Paradigmatic Change in Water Governance: An Analysis of the

Sustainable Development Goals (SDGs). Sustainability Science 13(4), 1155-66., DOI: 10.1007/s11625-017-0518-1.

Wiek Arnim and Kelli L. Larson (2012). Water, People, and Sustainability-A Systems Framework for Analyzing and Assessing Water Governance

Regimes. Water Resources Management 26(11), 3153-71.

Wilder Margaret and Patricia Romero Lankao (2006). Paradoxes of Decentralization: Water Reform and Social Implications in Mexico. World

Development 34(11), 1977-95. https://linkinghub.elsevier.com/retrieve/pii/S0305750X06001367.

Wymann von Dach S., Bracher C., Peralvo M., Perez K. and Adler C. (2018). Leaving No One in Mountains Behind. Localizing the SDGs for

Resilience of Mountain People and Ecosystems. Issue Brief on Sustainable Mountain Development. Bern. https://boris.unibe.ch/120130/1/Wymann_

et_al_2018_Issue_Brief_Leaving_no_one_in_mountains_behind.pdf.

Xue Lan, Lingfei Weng and Hanzhi Yu (2018). Addressing Policy Challenges in Implementing Sustainable Development Goals through an

Adaptive Governance Approach: A View from Transitional China. Sustainable Development 26(2): 150-58., DOl: 10.1002/sd.1726.

Young Oran R. (2003). Environmental Governance: The Role of Institutions in Causing and Confronting Environmental Problems. International

Environmental Agreements 3, 377-93.

Zuindeau Bertrand (2006). Spatial Approach to Sustainable Development: Challenges of Equity and Efficacy. Regional Studies 40(5): 459-70.,

DOl: 10.1080/00343400600757437. 